Review

\title{
Parvovirus B19 Infection in Solid Organ Transplantation: Report of A Case and A Review
}

\author{
Margaret E. Newman, Kenneth Pursell, David Pitrak *
}

Section of Infectious Diseases and Global Health, University of Chicago Medicine, USA; E-Mails: margaret.newman@uchospitals.edu; kpursell@medicine.bsd.uchicago.edu; dpitrak@medicine.bsd.uchicago.edu

* Correspondence: David Pitrak; E-Mail: dpitrak@medicine.bsd.uchicago.edu

Academic Editor: Maricar Malinis

Special Issue: Diagnosis and Management of Infections in Solid Organ Transplant Recipients

OBM Transplantation

2019, volume 3, issue 1

doi:10.21926/obm.transplant.1901040
Received: November 05, 2018

Accepted: January 15, 2019

Published: January 21, 2019

\begin{abstract}
Infection with parvovirus B19 is common, with up to 55\% of adults showing seropositive evidence of prior infection. Clinical disease can occur due to acute infection, chronic persistent viremia, rarely secondary infection, or possibly viral reactivation of latent virus. The clinical presentation of primary infection depends on age, the presence of a hematologic condition, and immune status. We report a renal transplant recipient who developed transfusion dependent anemia refractory to erythropoietin that responded to IgG replacement, although he had a relapsing course. It is an uncommon infection in solid organ transplant (SOT) recipients that has atypical features, usually presenting with pure red cell aplasia which is refractory to erythropoietin (EPO) and which can be transfusion dependent. Plasma polymerase chain reaction (PCR) measurement of DNA, both qualitative and quantitative, can be very helpful for diagnosis, but a negative test does not exclude infection. In those cases, bone marrow biopsy may be needed to document the viral infection. Due to immunosuppression, SOT recipients may not be able to mount a measurable antibody response; hence serologic diagnosis by antibody detection may be unreliable. Other end organ disease is even more unusual manifestation of parvovirus infection, but it can occur,
\end{abstract}

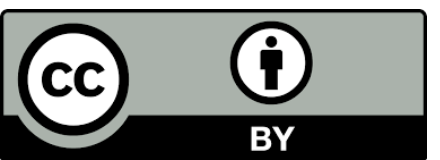

(C) 2019 by the author. This is an open access article distributed under the conditions of the Creative Commons by Attribution License, which permits unrestricted use, distribution, and reproduction in any medium or format, provided the original work is correctly cited. 
most commonly in immunocompromised individuals. Intravenous immunoglobulin (IVIG) replacement therapy appears to be most effective treatment, although there may also be a role for reduction in immunosuppression. The ability to prevent this unusual infection may be difficult as most patients who transmit the disease are often asymptomatic.

\section{Keywords}

Parvovirus B19; solid organ transplantation; anemia; red cell aplasia

\section{Introduction}

Since it was first discovered in 1974 by Cossart et al., human parvovirus B19 has been implicated in many serious infections in immunocompromised individuals, as well as innumerable childhood exanthems $[1,2]$. It is a common infection in childhood, with erythema infectiosum being the most typical clinical syndrome. Because of this ubiquity, most adults have been exposed to parvovirus B19 and have IgG antibodies to the virus. In fact, 55\% of individuals aged $11-15$ years old and approximately $90 \%$ of individuals over 71 years old have serologic evidence of IgG to parvovirus B19 [3]. Although the risk of infection is greatest in childhood, there is ongoing risk of infection throughout adulthood. In serologic studies of pregnant women, the annual rate of seroconversion in susceptible individuals was $1.5 \%[3,4]$. The presentation in adults is different than in children, with a clinical presentation often characterized by a form of polyarthritis that can mimic rheumatoid arthritis. Special populations can have other manifestations. Parvovirus is the major cause of transient aplastic crisis in patients with hemolytic syndromes. If infection occurs in pregnancy, the fetus can become infected and develop hydrops fetalis or congenital anemia. A similarity across these manifestations of parvovirus infection is that although antibodies are extremely common in the population, viremia is not.

The incidence of parvovirus B19 infection in SOT is not well established, as most of the literature involves case reports rather than large cohorts, and diagnostic testing is variable [5]. Screening is generally not recommended. Some longitudinal cohort studies estimate the prevalence of B19 infection in transplant recipients to be approximately 1-12\% [6-10]. Molecular surveillance studies have indicated that $23-31 \%$ of renal transplant patients may be viremic [11]. Despite many case reports, clinical parvovirus B19 is still considered a rare clinical complication of transplantation, though it can be potentially quite serious.

Infection most frequently occurs via transmission of the virus in respiratory secretions, but it may also be contracted through blood transfusion, bone marrow, or organ transplantation [12-14]. Nosocomial and congenital transmission have also been documented [15, 16]. While most adults have long-lived protective antibodies against parvovirus, severe infection may occur in individuals with depressed immune systems due to solid organ or bone marrow transplant, HIV, or other immunodeficiencies. The higher risk among transplant and other immunocompromised patients is thought to be related to both a lack of neutralizing antibodies as well as depressed cellular immune response [5, 17-20].

Parvovirus B19 is a single stranded DNA virus; the genome codes for with 3 highly conserved proteins: NS1, VP1, and VP2. There is over $85 \%$ genetic conservation of these proteins across a 
wide sample of virus samples, which explains why IgG antibodies against parvovirus offer substantial protection against future infection [2, 5, 21]. B19 was the first pathogenic human parvovirus discovered; more recently discovered human pathogen parvoviruses are considered less clinically significant due to their relative rarity.

We report a renal transplant recipient who developed transfusion dependent anemia refractory to erythropoietin that responded to IgG replacement therapy, although he had a relapsing course.

\section{Case Study}

A 53-year-old man with chronic renal failure from diabetes mellitus and hypertension underwent a cadaveric renal transplant. CMV status was donor seropositive, and recipient seropositive. He also had underlying cardiovascular disease and had suffered a non-ST elevated myocardial infarction (NSTEMI) in the early post-transplant period. For immunosuppression, he was receiving tacrolimus, mycophenolate mofetil, and prednisone. He was also taking trimethoprim-sulfamethoxazole (TMP-SMX) for Pneumocystis jirovecii pneumonia (PJP) prophylaxis. On day 1 post-transplant, his hemoglobin $(\mathrm{Hgb})$ was $8.9 \mathrm{~g} / \mathrm{dL}$, but the anemia gradually improved and his Hgb was $13.2 \mathrm{~g} / \mathrm{dL}$ by day 92 . His hemoglobin started to drop, however, after day 225 . On day 278 he presented to the hospital with chest pain and was admitted for an evaluation. He did not have an acute myocardial infarction, but he did have T-wave inversions in his inferior lead and a troponin value which peaked at $0.33 \mathrm{ng} / \mathrm{mL}$. At the time of presentation, the patient's Hgb was $7.0 \mathrm{~g} / \mathrm{dL}$, and it subsequently dropped to a low of $6.6 \mathrm{~g} / \mathrm{dL}$. His reticulocyte count was measured as $0.0 / \mu \mathrm{L}$. There was no evidence of bleeding. The white blood cell count was $6.3 \mathrm{~K} / \mu \mathrm{L}$ and the platelet count was $220 \mathrm{~K} / \mu \mathrm{L}$. The MCV was $85.9 \mathrm{fL}$. Serum iron level was 241 $\mathrm{mcg} / \mathrm{dL}$ (normal 40-160), total iron binding capacity $253 \mathrm{mcg} / \mathrm{dL}$ (normal 230-430), and the ferritin level 1,686 ng/mL (normal 20-300). The haptoglobin was measured at $49 \mathrm{ng} / \mathrm{dL}$ (normal 51-192). The erythropoietin level was measured at $488.5 \mathrm{mIU} / \mathrm{mL}$ (normal 4.0-26.0). Plasma PCR for CMV and EBV did not detect any viral DNA. A respiratory viral multiplex PCR panel was also negative. TMP-SMX and mycophenolate mofetil were held, while tacrolimus and prednisone were continued. Parvovirus antibodies were below threshold of detection by enzyme immune assay performed at Mayo Clinic Laboratories (IgM =0.09, negative < 0.9; IgG 0.42, negative < 0.9). Parvovirus B19 serologies had not been previously measured. Anemia and underlying cardiovascular disease were thought to contribute to abnormal electrocardiogram and troponin elevation; he received transfusion of two units of packed red blood cells for anemia. Posttransfusion, his $\mathrm{Hgb}$ was $8.9 \mathrm{~g} / \mathrm{dL}$, but this again dropped until he reached a nadir of 6.6 on day 296. After a plasma qualitative PCR for parvovirus B19 from day 285 came back positive for viral DNA (real-time PCR developed and performance characteristics determined at Mayo Clinic Laboratories), he was treated with two infusions of $80 \mathrm{~g}$ (approximately $1 \mathrm{~g} / \mathrm{kg}$ ) of IVIG two weeks apart. Between doses he underwent left heart catheterization and had a drug eluting stent placed in his right circumflex artery. He received another two doses of 80 grams of IVIG on day 341 and day 343.

The patient's qualitative parvovirus plasma PCR remained positive from day 285 to day 477 . He did not have a quantitative plasma PCR study sent until day 478, when his Hgb again dropped to $10.0 \mathrm{~g} / \mathrm{dL}$. He was retreated with $22.5 \mathrm{~g}$ (300 mg/kg) of IVIG. At that time, he had 23,256 copies 
parvovirus B19 DNA per $\mathrm{mL}$ plasma (performed by FOCUS Laboratories, CA). After this fifth infusion of IVIG, he developed fevers, chills, diffuse arthralgias and a macular rash on his lower extremities. His maximum temperature was $39.4^{\circ} \mathrm{C}$. He was started on empiric intravenous antibiotics, but cultures remained negative and the antibiotics were discontinued. His symptoms were attributed to immune complex disease. Although adverse reactions to IVIG are more common with the initial infusion, immune complex-related reactions may occur with any infusion as a result of high immunoglobulin A (IgA) or anti-Rh blood group antibodies [22].

By day 545, his quantitative serum parvovirus B19 DNA PCR had decreased to 3,389 copies/mL. At that time, he also had evidence of antibody response to parvovirus. His IgG optical density (OD) by EIA was 4.89, in part due to donor antibodies from IVIG, but he also now had an IgM OD of 1.22. He was also tested with a quantiferon-Tuberculosis (TB) Gold test and he had an excellent response to the mitogen control (mitogen - NIL of 6.61), suggesting appropriate lymphocyte response. From day 534 onward he maintained a normal Hgb above $13.5 \mathrm{~g} / \mathrm{dL}$ without any further doses of IVIG.

This case report demonstrates the difficulty of diagnosing parvovirus infection following solid organ transplantation. Patients often present with a sole symptom of anemia (and/or sequelae of anemia, as in our patient with cardiac symptoms), which may not resolve with transfusions alone. Resolution of parvovirus viremia and associated symptoms may require several doses of IVIG, which is not without potential adverse effects.

\section{Discussion}

\subsection{Magnitude of the Problem}

The most severe infections in the solid organ transplant recipient are those caused by human herpes viruses, particularly CMV, but also herpes simplex virus (HSV), varicella zoster virus (VZV), and Epstein-Barr virus (EBV). Adenovirus, BK virus, and the viral hepatitides are also important post-transplant viral pathogens. The frequency of clinical disease due to parvovirus B19 in solid organ transplant recipients is low. Screening is not recommended due to the infrequency of disease and lack of pre-emptive therapies to prevent disease [7, 23]. However, the potential for persistent or recurrent infection, as well as the potentially fatal manifestations, makes parvovirus B19 infection a relevant concern following transplantation. The most extensive review of parvovirus B19 in transplant recipients was conducted by Eid and colleagues from the Mayo Clinic [6]. This group did an analysis of institutional cases, a review of the literature, and performed plasma PCR for parvovirus B19 on stored samples from a cohort of solid organ and stem cell transplant recipients. Over a 15-year period, only 8 cases were identified (mean age 37.4), and none of the plasma samples from 47 patients who had undergone solid organ transplantation or allogeneic stem cell transplantation had detectable viral DNA. Their literature review through 2006 identified only 91 cases, with mean age of 35.2 years (+/-17.1 years standard deviation). Almost all patients had anemia. Death occurred in $3 \%$ of cases, all in patients with viral myocarditis. Other studies using parvovirus PCR have documented viremia in a higher proportion of renal transplant recipients, particularly those with anemia $[10,11]$. Patients with advanced HIV and lymphoproliferative disease are other immunosuppressed populations who are at risk for developing severe parvovirus infection $[24,25]$. 


\subsection{Clinical Presentation}

The usual presentation of parvovirus infection in solid organ transplant recipients, red cell aplasia, is atypical for other patients. Parvovirus B19 most frequently causes erythema infectiosum, or fifth disease, in children. In immunocompetent adults, the infection may manifest as fevers and symmetric arthralgias. Symptoms are typically present during viremia, and then resolve when neutralizing antibodies are produced $[5,7,21]$. Most immunocompetent adults will only have mild symptoms related to reticulocytopenia and/or transient anemia related to the red blood cell lifespan and reserve [15]. Red cell aplasia, however, is seen in patients with hemolytic syndromes due to rapid red cell turnover, as well as immunocompromised hosts due to poor immune response to infection [5].

There are case reports of other immunocompromised patients who have developed hepatitis, pneumonia, myocarditis, and allograft dysfunction. Allograft dysfunction associated with parvovirus B19 infection is thought to be related to non-specific immune responses to the virus $[26,27]$. Biopsies of renal transplant patients with parvovirus B19 infection often have thrombotic microangiopathy, but it is not completely clear that this is the mechanism by which infections lead to graft failure [28]. One review found that there was no difference in graft function of $31 \%$ of patients with positive parvovirus B19 DNA PCR and those without detectable virus [10]. Our patient did not have any of these end-organ complications.

Chronic, prolonged parvoviremia occurring in immunocompromised individuals has been reported in several case reports $[17,24,29,30]$. The inability to clear the viral infection is thought to be related mainly to a lack of neutralizing antibody production as well as some suppression of cellular immunity [30]. It is less clear how to define instances of secondary parvovirus B19 infection in which there is production of IgM and high viral load despite pre-existing evidence of IgG antibodies. In such cases, experts have offered conflicting explanations of latent viral reactivation versus secondary infection [25, 31-37]. One case report [35] performed genomic sequencing of the parvovirus B19 DNA and found that the patient was infected with the same rare genotype 2 on multiple occasions of viremia, which supports the explanation of reactivation, as it would be unlikely to encounter genotype 2 on multiple occasions. Other case reports describe a second acute parvovirus infection (with IgM and DNA viremia) in a healthy individual with existing IgG in the setting of community outbreak, but the higher incidence of recurrent infections in immunocompromised individuals suggests an immune defect (or immunosuppression effect) leading to susceptibility [31, 32, 34, 36]. A study of 126 serum samples analyzed with real-time multiplex viral PCR quantification assays found a low level B19 viremia of $0.8 \%$ among the cohort, suggesting that this virus can become latent, similar to related DNA viruses $[37,38]$ One argument against the potential for parvovirus B19 to reactivate is that the virus seems uncommon in elderly individuals, unlike other DNA viruses that are known to reactivate, such as VZV and adenovirus.

\subsection{Pathophysiology/Immunology}

Parvovirus is one of the viruses, along with herpesviruses, adenoviruses, and polyoma viruses, which can establish latency and reactivate when the host immune system is depressed [38]. Secondary symptomatic infection may also occur in patients with prior infection, and this has been reported in both immune competent and immune deficient individuals [31]. Acute primary 
infection in adults, including transplant patients, can also occur. During viremia, reticulocyte numbers fall characteristically. Lymphopenia, neutropenia, and thrombocytopenia may also occur. The lack of baseline serological data in most patients makes it difficult to determine if an individual patient has acute infection that does not clear due to a poor immune response, or reactivation of a latent infection due to depressed immunity, though IgG avidity may be useful for determining acuity of antibody production, if available [2,39]. It is also potentially possible for loss of neutralizing antibodies to occur, similar to the reverse seroconversion to hepatitis $B$ resulting in active hepatitis that can occur after transplantation [17, 40]. Hypogammaglobulinemia is a common occurrence after transplantation, and it may be difficult to distinguish etiology as viral versus immune-mediated. We did not have baseline IgG levels or IgG avidity in the patient in our report.

The virus infects erythroid cells through its tropism for the $P$ antigen receptor on their surfaces. The absence of the $P$ antigen on erythroid cells has been associated with resistance to parvovirus B19 infection. This infection of the erythroid cells is characterized by giant pronormoblasts with intranuclear inclusions $[6,7,25]$. Once the virus enters the cell and begins replicating, the host natural immune response is to release cytokines as a generalized inflammatory response while $B$ cells develop virus-specific antibodies against parvovirus B19. Antibodies are responsible for viral clearance and usually offer lifelong protection in immunocompetent individuals. T lymphocytes also play a role in the immune response, with $\mathrm{CD} 8+\mathrm{T}$ cells thought to mount a response predominantly against the NS1 protein, and CD4+ T cells directing a response against the VP1 and VP2 capsid proteins of the virus $[18,41]$. Long-lived CD8+ T cells against parvovirus B19 have been detected in individuals two years after infection, suggesting a role for the cellular immune system in durable immunity as well as acute response $[20,30]$.

\subsection{Diagnosis}

In immunocompetent patients, detection of parvovirus B19 serologies (IgM and $\operatorname{lgG}$ ) is sufficient to make a diagnosis. Diagnosis is more challenging in immunocompromised patients, as they may have an absent or delayed antibody response to the infection. As described above, secondary reinfection and reactivation of latent infection also seem possible. Initial work up of suspected parvovirus infection should include IgM and IgG antibodies. Plasma PCR can document viremia, but a negative result does not necessarily exclude the diagnosis [7]. Either qualitative or quantitative serum PCR is sufficient to document viremia. If the plasma PCR is negative, bone marrow biopsy may be necessary. Bone marrow biopsy can be examined for morphologic findings of parvovirus B19 infection as well as presence of parvovirus B19 DNA [29]. The findings of arrested erythroid maturation, as evidenced by the presence of giant pronormoblasts with inclusions, are pathognomonic for the disease $[6,7,27]$. Bone marrow biopsy may be particularly helpful when serologies and plasma PCR are negative but clinical suspicion for parvovirus infection remains high.

\subsection{Therapy}

There is no specific antiviral therapy for the treatment of parvovirus B19 infection. Numerous studies have shown the benefit of IVIG dosing for immunocompromised patients with severe parvovirus B19 infection, which is likely beneficial due to the presence of pooled donor parvovirus 
B19 IgG antibodies in the infusion [7]. The most typical dose used successfully in the literature is $0.4 \mathrm{~g} / \mathrm{kg} /$ day $\times 5$ doses, or $1 \mathrm{~g} / \mathrm{kg} /$ day $\times 2-3$ doses $[42,43]$. In addition to boosting humoral immunity with IVIG, reducing immunosuppression has also been considered a useful strategy for parvovirus B19 infection. Specifically, reducing immunosuppression that affects T cell lymphocytes (such as switching from tacrolimus to cyclosporine) is thought to improve the immune response to parvovirus B19 infection [6, 19, 44].

One caveat to these treatment recommendations, as noted by several reviews of parvovirus B19 infection in renal transplant patients, is the risk of nephrotoxicity with IVIG [10, 43]. In addition, as in our case, patients may develop rash and polyarthritis associated with either therapy or infection.

\subsection{Monitoring Response to Therapy and Determining the Duration of Therapy}

The main clinical manifestation of parvovirus infection for our transplant patient was anemia requiring transfusion, so monitoring the patient's hemoglobin was our key monitoring parameter. However, due to the long half-life of red blood cells (RBCs), including transfused RBCs, it is difficult to assess the activity of the ongoing infection. Qualitative PCR documented ongoing viremia in our patient, and he still had a fairly high plasma viral load at day 478, despite clinical improvement. It has been shown that PCR can detect DNA months after infection, even in immunocompetent hosts [45].

In our case we also checked serologies later in the course of the patient's infection. Although the IgG antibodies to parvovirus would likely originate from the IVIG replacement therapy, the apparent ability to mount an IgM antibody response indicated that our patient was eventually able to produce an immune response to the infection.

The role of T-cell response to parvovirus B 19 is unknown, but an immune reaction has been detected. There is no data on the incidence of parvovirus B19 in patients who are generally immunosuppressed by non-specific measures of cell mediated immunity, such as the immunoassay. There is no quantiferon test for parvovirus B19, similar to that for TB or cytomegalovirus (CMV). Our patient, however, did have a very robust IFN- $\nu$ response to the mitogen control for the quantiferon-TB test, indicating some integrity of his cell-mediated immunity.

\subsection{Prevention}

Parvovirus B19 is transmitted through respiratory secretions due to viral shedding in viremic patients. Nosocomial infections have been reported [15]. Patients with active parvovirus infection should be isolated in the hospital. Since many patients with active infection are asymptomatic, and patients can be infectious prior to the onset of symptoms, isolation precautions will not eliminate secondary transmissions. Furthermore, although respiratory symptoms are the typical initial symptoms, the multiplex PCR respiratory viral panel does not include a parvovirus target. There are no other guidelines that recommend other strategies to prevent parvovirus infection. As neutralizing antibodies are protective and there is little antigenic variation, prophylactic immunization against this virus seems feasible. Promising vaccine candidates against parvovirus B19 are currently in development $[46,47]$. 


\section{Conclusion}

In summary, parvovirus B19 is an uncommon infection that has atypical features in solid organ transplant recipients as compared to immunocompetent hosts. It is possible that parvovirus may become latent and later reactivate, though there is more evidence that secondary infection and chronic infection (persistent viremia that does not clear due to impaired immunity) occur in immunocompromised individuals. Infected patients may present with anemia (or pure red cell aplasia) that is refractory to EPO. Diagnosis by antibody detection is limited. Plasma PCR, qualitative and quantitative, is very helpful, but a negative test does not exclude infection. IVIG replacement therapy appears to be most effective, although there may be a role for reduction in immune suppression. The ability to prevent this unusual infection is limited, as patients who are asymptomatic may transmit the disease.

\section{Acknowledgments}

We would like to acknowledge the clinical care provided by Dr. Mary Ellen Acree, Section of Infectious Diseases, NorthShore University Health System.

\section{Author Contributions}

All authors contributed extensively to the work presented in this paper.

\section{Funding}

The authors received no support or funding.

\section{Competing Interests}

The authors have declared that no competing interests exist.

\section{References}

1. Cossart YE, Field AM, Cant B, Widdows D. Parvovirus-like particles in human sera. Lancet. 1975; 1: 72-73.

2. Qiu J, Soderlund-Venermo M, Young NS. Human Parvoviruses. Clin Microbio Rev. 2017; 30: 43-113.

3. Cohen BJ, Buckley MM. The prevalence of antibody to human parvovirus B19 in England and Wales. J Med Microbiol. 1998; 25: 151-153.

4. Koch WC, Adler SP. Human parvovirus B19 infection in women of childbearing age and within families. Pediatr Infect Dis J. 1989; 8: 83-87.

5. Waldman M, Kopp JB. Parvovirus B19 and the kidney. Clin J Am Soc Nephrol. 2007; 2: S47-S56.

6. Eid AJ, Brown RA, Patel R, Razonable RR. Parvovirus B19 infection after transplantation: a review of 98 cases. Clin Infect Dis. 2006; 43: 40-48.

7. Broliden K. Parvovirus B19 infections in pediatric solid organ and bone marrow transplants. Pediatr Transplant. 2001; 5: 320-330. 
8. Gallinella G, Manaresi E, Ventuoli S, Grazi GL, Musiani M, Zerbini M. Occurrence and clinical role of active parvovirus B19 in transplant recipients. Eur J Clin Microbiol Infect Dis. 1999; 18: 811-813.

9. Zolnourian ZR, Curran MD, Rima BK, Coyle PV, O'Neill HJ, Middleton D. Parvovirus B19 in kidney transplant patients. Transplantation. 2000; 69: 2198-2202.

10. Ki CS, Kim IS, Kim JW, Lee NY, Kim SH, Lee KW, et al. The incidence and clinical significance of human parvovirus B19 infection in kidney transplant recipients. Clin Transplant. 2005; 19: 751-755.

11. Cavallo R, Merlino C, Re D, Bollero C, Bergallo M, Lembo D, et al. B19 virus infection in renal transplant patients. J Clin Virol. 2003; 26: 361-368.

12. Anderson MJ, Higgins PG, Davis LR, Willman JS, Jones SE, Kidd IM, et al. Experimental parvoviral infection in humans. J Infect Dis. 1985; 152: 257-265.

13. Heegaard ED, Laub PB. Parvovirus B19 transmitted by bone marrow. Br J Haematol. 2000; 111: 659-661.

14. Laurenz M, Winkelmann B, Roigas J, Zimmering M, Querfeld U, Muller D. Severe parvovirus B19 encephalitis after renal transplantation. Pediatr Transplant. 2006; 10: 978-981.

15. Ozeki M, Fukushima T, Ohzeki M, Sasaki T, Kashihara N. A nosocomial parvovirus B19 infection-induced transient aplastic crisis in a patient with chronic renal failure. Clin Nephrol. 2006; 65: 141-143.

16. Brown KE, Green SW, Antunez de Mayolo J, Bellanti JA, Smith SD, Smith TJ, et al. Congenital anemia after transplancental B19 parvovirus infection. Lancet. 1994; 343: 895-896.

17. Kurtzman GJ, Cohen BJ, Field AM, Oseas R, Blease RM, Young NS. Immune response to B19 parvovirus and an antibody defect in persistent viral infection. J Clin Invest. 1989; 84: 11141123.

18. Von Poblotzki A, Gerdes C, Reischl U, Wolf H, Modrow S. Lymphoproliferative responses after infection with human parvovirus B19. J Virol. 1996; 70: 7327-7330.

19. Renoult E, Bachelet C, Krier-Coudert MJ, Diarrassouba A, Andre JL, Kessler M. Recurrent anemia in kidney transplant recipients with parvovirus B19 infection. Transplant Proc. 2006; 38: 2321-2323.

20. Isa A, Kasprowicz V, Norbeck O, Loughry A, Jeffery K, Broliden K, et al. Prolonged activation of virus-specific CD8+ T cells after acute B19 infection. PLoS Med. 2005; 2: e343.

21. Gosset C, Viglietti D, Hue K, Antoine C, Glotz D, Pillebout E. How many times can parvovirus B19-related anemia recur in solid organ transplant recipients? Transplant Infect Dis. 2012; 14: E64-E70.

22. Gui $Y$, Tian $X$, Wang $X$, Xiao Z. Adverse effects of immunoglobulin therapy. Front Immunol. 2018; 9: 1299.

23. Eid AJ, Chen SF, and the AST Infectious Diseases Community of Practice. Human parvovirus B19 in solid organ transplantation. Am J Transplant. 2013; 13: 201-205.

24. Frickhofen N, Abkowitz JL, Safford M, Berry JM, Antunez-de-Mayolo J, Astrow A, et al. Persistent B19 parvovirus infection in patients infected with human immunodeficiency virus type 1 (HIV-1): a treatable cause of anemia in AIDS. Ann Intern Med. 1990; 113: 926-933.

25. Bremner JA, Beard S, Cohen BJ, Alimenti A, Cantiniaux B, Levy J. Secondary infection with parvovirus B19 in an HIV-positive patient. AIDS. 1993; 7: 1131-1132. 
26. Cainelli $F$, Vento $S$. Infections and solid-organ transplant rejection: a cause-and-effect relationship? Lancet Infect Dis. 2002; 2: 645.

27. Subtirelu MM, Flynn JT, Schechner RS, Pullman JM, Feuerstein D, Del Rio M. Acute renal failure in pediatric kidney allograft recipient treated with intravenous immunoglobulin for parvovirus B19 induced red cell aplasia. Pediatr Transplant. 2005; 9: 801-804.

28. Halentera I, Egli A, Koskinen P, Lauenschlager I, Hirsch HH. Viral impact on long-term kidney graft function. Infect Dis Clin N Am. 2010; 24: 339-371.

29. Koda Y, Mori T, Kato J, Kohashi S, Kikuchi T, Mitsuhashi T, et al. Persistent parvovirus B19 infection resulting in red cell aplasia after allogeneic stem cell transplantation. Transplant Infect Dis. 2013; 15: E239-E242.

30. Lindblom A, Isa A, Norbeck O, Wolf S, Johansson B, Broliden K, et al. Slow clearance of human parvovirus B19 viremia following active infection. Clin Infect Dis. 2005; 41: 1201-1203.

31. Kaufmann J, Buccola JM, Stead W, Rowley C, Wong M, Bates CK. Secondary symptomatic parvovirus B19 infection in healthy adults. J Gen Intern Med. 2007; 22: 877-878.

32. Sterpu R, Icou H, Mahe I, Mortier E. Reactivation of parvovirus B19 in an HIV-infected woman [abstract only]. Le revue de medecine interne. 2014; 35: 396-398.

33. Karrasch M, Felber J, Keller PM, Kletta C, Egerer R, Bohnert J, et al. Primary Epstein-barr infection and probably parvovirus B19 virus reactivation resulting in fulminant hepatitis and fulfilling five of eight criteria for hemophagocytic lymphohistiocytosis. Int J Infect Dis. 2014; 28: 143-146.

34. Xiao C, Wang CX, Liu LS, Fu Q. Clinical investigation of human parvovirus B19 infection after renal transplantation in China. Transplant Proc. 2013. 45: 1593-1599.

35. Liefeldt L, Plentz A, Klempa B, Kershaw O, Endres AS, Raab U, et al. Recurrent high-level parvovirus B19 /genotype 2 viremia in a renal transplant recipient analyzed by real-time PCR for simultaneous detection of genotypes 1 and 3. J Med Virol. 2005; 75: 161-169.

36. Moudgil A, Shidban H, Nast CC, Bagga A, Aswad A, Graham SL, et al. Parovirus B19 infectionrelated complications in renal transplant recipients: treatment with intravenous immunoglobulin. Transplantation. 1997; 64: 1847-1850.

37. Compston LI, Sarkobie F, Li C, Candotti D, Opare-Sem O, Allain J. Multiplex real-time PCR for the detection and quantification of latent and persistent viral genomes in cellular or plasma blood fractions. J Virol Methods. 2008, 151: 47-54.

38. Traylen CM, Patel HR, Fondaw W, Mahatme S, Williams JF, Walker LR, et al. Virus reactivation: a panoramic view in human infections. Future Virol. 2011; 6: 451-463.

39. Al-Khaldi N,Watson AR, Harris A, Irving WL. Dual infection with human herpesvirus type 6 and parvovirus B19 in a renal transplant recipient. Pediatr Nephrol. 1994; 8: 349-350.

40. Ozaras R, Ar C, Ongoren S, Mete B, Tabak F, Mert A, Ozturk R. Acute hepatitis B despite a previous high titer of anti-HBs. Hepatol Int. 2010; 4: 530-532.

41. Tolfvenstam T, Oxenius A, Price DA, Shacklett BL, Spiegel HM, Hedman K, et al. Direct ex vivo measurement of CD8+ T lymphocyte responses to human parvovirus B19. J Virol. 2001; 75: 540-543.

42. Heegaard ED, Brown KE. Human parvovirus B19. Clin Microbiol Rev. 2002; 15: 485-505.

43. Crabol Y, Terrier B, Rozenberg F, Pestre V, Legendre C, Hermine $O$, et al. Intravenous immunoglobulin therapy for red cell aplasia related to parvovirus B19 infection: a review of 10 cases in the literature. Clin Infect Dis. 2013; 56: 968-977. 
44. Wong TY, Chan PK, Leung CB, Szeto CC, Tam JS, Li PK. Parvovirus B19 infection causing red cell aplasia in renal transplantation on tacrolimus. Am J Kidney Dis. 1999; 34: 1132-1136.

45. Oramas DM, Setty S, Yeldandi V, Cabrera J, Patel T. A case report of parvovirus B19 in a renal allograft. Int J Surg Path. 2017; 25: 648-651.

46. Chandramouli S, Medina-Selby A, Coit D, Schaefer M, Spencer T, Brito LA, et al. Generation of a parvovirus B19 vaccine candidate. Vaccine. 2013; 31: 3872-3878.

47. Penkert RR, Young NS, Surman SL, Sealy RE, Rosch J, Dormitzer PH, et al. Saccharomyces cerevisiae-derived virus-like particle parvovirus B19 vaccine elicits binding and neutralizing antibodies in mouse model for sickle cell disease. Vaccine. 2017; 35: 3615-3620.

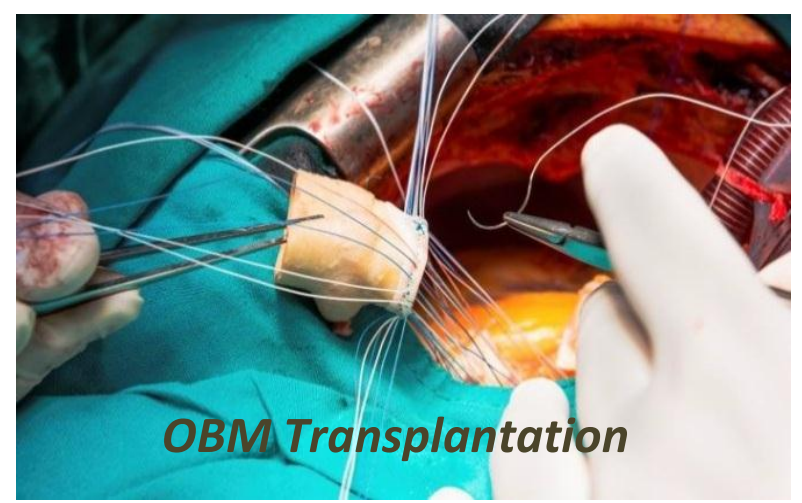

Enjoy OBM Transplantation by:

1. Submitting a manuscript

2. Joining in volunteer reviewer bank

3. Joining Editorial Board

4. Guest editing a special issue

For more details, please visit:

http://www.lidsen.com/journals/transplantation 